\title{
False Morphology of Aerogels Caused by Gold Coating for SEM Imaging
}

\author{
Laura Juhász ${ }^{1,2} \mathbb{D}$, Krisztián Moldován ${ }^{3,4} \mathbb{D}$, Pavel Gurikov ${ }^{5} \mathbb{D}$, Falk Liebner ${ }^{6} \mathbb{D}$, István Fábián ${ }^{3} \mathbb{D}$, \\ József Kalmár ${ }^{3, *,+}$ (D) and Csaba Cserháti ${ }^{1, *,+}$ (D)
}

1 Department of Solid State Physics, University of Debrecen, Egyetem sqr. 1, H-4032 Debrecen, Hungary; juhasz.laura@science.unideb.hu

2 Doctoral School of Physics, University of Debrecen, Egyetem sqr. 1, H-4032 Debrecen, Hungary

3 MTA-DE Redox and Homogeneous Catalytic Reaction Mechanisms Research Group, Department of Inorganic and Analytical Chemistry, University of Debrecen, Egyetem sqr. 1, H-4032 Debrecen, Hungary; moldovan.krisztian@science.unideb.hu (K.M.); ifabian@science.unideb.hu (I.F.)

4 Doctoral School of Chemistry, University of Debrecen, Egyetem sqr. 1, H-4032 Debrecen, Hungary

5 Laboratory for Development and Modelling of Novel Nanoporous Materials, Hamburg University of Technology, Eißendorfer Straße 38, 21073 Hamburg, Germany; pavel.gurikov@tuhh.de

6 Institute for Chemistry of Renewable Resources, University of Natural Resources and Life Sciences, Vienna (BOKU), Konrad-Lorenz-Straße 24, A-3430 Tulln, Austria; falk.liebner@boku.ac.at

* Correspondence: kalmar.jozsef@science.unideb.hu (J.K.); cserhati.csaba@science.unideb.hu (C.C.); Tel.: +36-52-512-900 (J.K.); +36-52-316-073 (C.C.)

+ These authors contributed equally to the work.

check for

updates

Citation: Juhász, L.; Moldován, K.; Gurikov, P.; Liebner, F.; Fábián, I.; Kalmár, J.; Cserháti, C. False

Morphology of Aerogels Caused by Gold Coating for

SEM Imaging. Polymers 2021, 13, 588.

https://doi.org/10.3390/polym13040588

Academic Editor: Iolanda De Marco

Received: 7 January 2021

Accepted: 11 February 2021

Published: 16 February 2021

Publisher's Note: MDPI stays neutral with regard to jurisdictional clai$\mathrm{ms}$ in published maps and institutional affiliations.

Copyright: $\odot 2021$ by the authors. Licensee MDPI, Basel, Switzerland. This article is an open access article distributed under the terms and conditions of the Creative Commons Attribution (CC BY) license (https:// creativecommons.org/licenses/by/ $4.0 /)$.

\begin{abstract}
The imaging of non-conducting materials by scanning electron microscopy (SEM) is most often performed after depositing few nanometers thick conductive layers on the samples. It is shown in this work, that even a $5 \mathrm{~nm}$ thick sputtered gold layer can dramatically alter the morphology and the surface structure of many different types of aerogels. Silica, polyimide, polyamide, calcium-alginate and cellulose aerogels were imaged in their pristine forms and after gold sputtering utilizing low voltage scanning electron microscopy (LVSEM) in order to reduce charging effects. The morphological features seen in the SEM images of the pristine samples are in excellent agreement with the structural parameters of the aerogels measured by nitrogen adsorption-desorption porosimetry. In contrast, the morphologies of the sputter coated samples are significantly distorted and feature nanostructured gold. These findings point out that extra care should be taken in order to ensure that gold sputtering does not cause morphological artifacts. Otherwise, the application of low voltage scanning electron microscopy even yields high resolution images of pristine non-conducting aerogels.
\end{abstract}

Keywords: mesoporous materials; aerogels; electron microscopy; gold sputtering; aggregation

\section{Introduction}

Aerogels obtained by sol-gel and dissolution-coagulation techniques and final supercritical drying are solid functional materials of extremely high porosities and low densities. These properties are utilized in a wide range of applications including advanced thermal insulation, catalysis, manufacture of electrode materials, high-capacity adsorbents, drug delivery and tissue engineering [1,2]. Functional aerogels are prepared from a large variety of structural materials, such as inorganic oxides (e.g., silica, alumina, titania), carbohydrate polymers (e.g., cellulose, alginate, starch, chitosan, pectin), proteins (e.g., collagen, casein, egg yolk), synthetic polymers (e.g., polyimide, polyamide, polyurea) or carbon (e.g., amorphous carbon, graphene) [3-12].

In general, aerogels obtained by supercritical drying feature the best preserved threedimensional structure of the precursor gel among all drying approaches. Hence, structural elements, including variations in the geometry of the network forming entities down to the nanoscale, can be differentiated. These differences in fine structure are related to the 
chemical composition of the source material(s) and the conditions of gel syntheses [13-16]. The archetypes of aerogels (silica, cellulose, alginate, polyurea, etc.) are either composed of small globular primary units of a few to a few tens of nanometers in diameter, or cylindrical fibrils of thicknesses in approximately the same size range [17-19]. However, some carbon based and polymer aerogels consist of flake-like flat nanostructures [20-22]. The pore systems of the aerogels in terms of void fraction, geometry, size distribution and degree of interconnectivity is predetermined by the architectures of their solid backbones [14,23]. The pore sizes vary between the micropore and the mesopore range, and the shapes of the pores can be spherical, cylindrical to slit-like.

The fundamental macroscopic properties (heat conductivity, compressive strength, bulk density, accessible specific surface area, total pore volume, permeability of pores, etc.) that determine the performances of the aerogels in practical applications are directly related to their microstructures [24-27]. Evidently, understanding functionality related structureproperties relationships are of key importance for designing new materials for specific advanced applications [28-31]. Furthermore, the understanding of the microstructures of aerogels enables high level theoretical simulations of their macroscopic properties [32,33].

Because of these reasons, significant efforts have been made to thoroughly characterize the nanostructured interior of these sensitive materials. Imaging the morphology by scanning electron microscopy (SEM), and assessment of pore characteristics by nitrogen adsorption-desorption porosimetry are key analytical procedures [34-36]. These techniques, however, require extensive care to ensure that the results are representative for the true interior of the materials, and exclude any possible artifacts. Erroneous conclusions with regard to nanostructures and morphologies of aerogels would jeopardize or even mislead time-consuming simulation efforts, and evidently, falsify structure-property relationship theories.

In this study, we systematically evaluate the performance of SEM applied to image the nanostructures of several different types of non-conducting aerogels (silica, silica hybrids, calcium-alginate, polyimide, polyamide, cellulose). The investigation of non-conducting materials commonly requires the deposition of a few nanometers thick conductive coating on the surfaces of the nanostructured samples. Here, we present clear evidence that the sputtering of gold onto the surfaces of non-conducting aerogels can significantly alter their nanostructures, thus leading to erroneous conclusions with regard to their morphologies. The imaging of pristine (uncoated) aerogel samples is also performed by using a special microscopy setup, and the observed morphological features are correlated to structural parameters derived from $\mathrm{N}_{2}$ adsorption-desorption porosimetry measurements [37].

Aerogel samples were characterized by Low Voltage Scanning Electron Microscopy (LVSEM). The advantage of using LVSEM has been discussed since the end of 1980s [38]. Currently, even entry-level instruments can image at low $\mathrm{kV}(1-5 \mathrm{kV})$ without much effort. This was not the case earlier. In addition, in the past, SEM instruments had significantly lower imaging resolution at low $\mathrm{kV}$. The solution to this-besides the Field Emission Gun (FEG) source-are unique electron optical elements, as well as the annular in-column detector system developed by Zeiss with the GEMINI column at the beginning of 1990 . This provides low $\mathrm{kV}$ with a very high probe current and maintains a very small probe diameter that gives a very high resolution with great signal to noise ratio and minimal sample damage. Today almost all SEM manufacturers apply these technical innovations in order to expand the capabilities of their instruments. In the present paper, we implement the newest results and innovations that are available on the market for a mainstream user.

\section{Experimental}

\subsection{Preparation of Aerogels}

Silica, silica-casein hybrid, silica-gelatin hybrid, Ca-alginate, polyimide, polyamide, $\mathrm{Ca}$ (II) crosslinked polyamide and cellulose aerogels were prepared using recipes previously published in the literature [20-22,39-45]. The essential summaries of the synthetic procedures are given in the Supplementary Meterials. 


\subsection{Characterization of Aerogels}

The main goal of the experiments was to investigate the effect of gold sputtering on the morphologies of different aerogels. The investigation was performed in four steps. First, each aerogel was imaged by SEM in its pristine form without gold coating. Second, a ca. $5 \mathrm{~nm}$ thick gold layer was deposited on the surfaces of the aerogels by using a conventional sputtering instrument (BIO-RAD SEM Coating Unit PS3, BIO-RAD Laboratories Ltd., Hercules, CA, USA), and the sample was imaged again. The third and fourth steps were repeating the deposition procedure in order to obtain thick, $16 \mathrm{~nm}$ and subsequently $32 \mathrm{~nm}$ coating layers before imaging. Gold deposition was carried out in $21 \mathrm{~Pa}$ of $\mathrm{Ar}$ and the sputtering rate was $0.53 \mathrm{~nm} \mathrm{~s}^{-1}$. The deposition rate was precisely measured in independent experiments on various substrates. The thickness of deposited gold was verified by profilometer (AMBIOS XP-I) [46-50].

The samples were investigated using a ThermoFisher Scientific Scios 2 dual beam microscope. The equipment is built with an acceleration tube, a unique in-lens Trinity detector system, and a retarding-field option. Taking advantage of this setup, low voltage scanning electron microscopy (LVSEM) technique was applied to make high-resolution images of the different aerogel samples, as detailed in the next subsection. An acceleration voltage of $1-2 \mathrm{kV}$ and $2-5 \mathrm{~mm}$ working distance was typically used. The investigation of the gold coated samples was carried out by using the same conditions as for the uncoated (pristine) ones. The samples were fixed on vacuum-resistant carbon tape. Fresh fracture surfaces were investigated far from the point of splitting the aerogel monolith.

Nitrogen adsorption-desorption porosimetry measurements were performed with a Quantachrome Nova 2200e surface area and porosity analyzer Quantachrome Instruments, Boynton Beach, FL, USA). All samples were degassed in vacuum at $60^{\circ} \mathrm{C}$ for $24 \mathrm{~h}$ before the measurements. Raw data was evaluated with the NovaWin 11.0 software (Quantachrome Instruments, Boynton Beach, FL, USA). Total surface area was calculated according to the Brunauer-Emmett-Teller (BET) model. Pore size distribution plots were constructed using the Barret-Joyner-Halenda (BJH) method.

\subsection{Low Voltage Scanning Electron Microscopy (LVSEM)}

The nanostructures of the aerogel samples were investigated with a Field Emission Scanning Electron Microscope (FESEM) [51,52]. Scanning electron microscopy operating at electron energies below $5 \mathrm{keV}$ is usually termed Low Voltage Scanning Electron Microscopy (LVSEM) [53]. The advantages of low acceleration voltage derive directly from the energy dependence of the electron-specimen interactions.

The penetration depth of the impinging electrons decreases with decreasing energy due to the reduced electron range, that is, the excitation volume shrinks in the specimen. The secondary electron (SE) yield increases because of the reduced electron range. The SEs that are generated near the surface can easily escape, which increases the SE yield. Because of the increasing SE yield, there should be a critical acceleration voltage for a given specimen where the amount of the incoming and the emitted electrons are balanced, and consequently, the specimen current equals to zero. This means that at this particular electron energy, no electric conductivity of the specimen is required. Ideally, imaging of electric insulators without conductive coating becomes possible. Further considerations on LVSEM technology are given in Supplementary Meterials.

\section{Results and Discussion}

Selected key structural parameters of the set of inorganic, biopolymer, organic and hybrid aerogels investigated in this study are complied in Table 1 . The results of the $\mathrm{N}_{2}$ gas porosimetry characterization of the different types of aerogels are summarized in the form of specific surface area $\left(S_{\mathrm{BE}}\right)$, mean pore size and total pore volume. The complete porosimetry reports are given in the Supplementary Meterials. It is clearly seen from Table 1 , that the studied aerogels are significantly different from each other not only regarding their structural materials, but also in the sense of very distinct morphologies. 
Table 1. Structural parameters derived from $\mathrm{N}_{2}$ gas adsorption-desorption porosimetry data.

\begin{tabular}{ccccccccc}
\hline Parameter & Silica & $\begin{array}{c}\text { Silica- } \\
\text { Gelatin }\end{array}$ & $\begin{array}{c}\text { Silica- } \\
\text { Casein }\end{array}$ & $\begin{array}{c}\text { Ca- } \\
\text { Alginate }\end{array}$ & $\begin{array}{c}\text { Poly- } \\
\text { Imide }\end{array}$ & $\begin{array}{c}\text { Poly- } \\
\text { Amide }\end{array}$ & $\begin{array}{c}\text { Poly- } \\
\text { Amide } \\
\text { (Ca(II)) }\end{array}$ \\
\hline $\begin{array}{c}\text { Specific } \\
\text { surface area }\left(\mathrm{m}^{2} \mathrm{~g}^{-1}\right)\end{array}$ & 898 & 742 & 750 & 544 & 297 & 245 & 251 & BET \\
$\begin{array}{c}\text { Mean pore } \\
\text { size (nm) }\end{array}$ & 15 & 14 & 17 & 42 & 3.8 & 3.4 & 4.3 & BJH \\
$\begin{array}{c}\text { Total pore } \\
\text { volume }\left(\mathrm{cm}^{3} \mathrm{~g}^{-1}\right)\end{array}$ & 7.5 & 3.2 & 3.2 & 7.8 & 0.8 & 0.8 & 0.7 & BJH \\
C-constant & 109 & 62 & 71 & - & 55 & 45 & 59 & BET \\
\hline
\end{tabular}

Microscopy images of pristine (uncoated) and gold coated silica aerogel samples are presented in Figure 1. Sputtering even a thin, $5 \mathrm{~nm}$ gold layer results in the formation of artificial structural elements on the aerogel surface, and a $16 \mathrm{~nm}$ thick layer significantly modifies the morphology of silica aerogel. The initial snowflake-like network of pristine silica aerogel disappears under the Au coating [54]. Globular Au nanoparticles similar in size to the primary silica globules develop on the surface after sputtering $5 \mathrm{~nm}$ thick gold (Figure 1b). Following a second round of sputtering, the Au particles are considerably larger due to nucleation, and they completely hide the pristine structure of silica aerogel (Figure 1c) [46-48]. The same phenomenon was observed in the case of other silica-based aerogels, such as silica-casein and silica-gelatin hybrids (Figures 2 and 3).

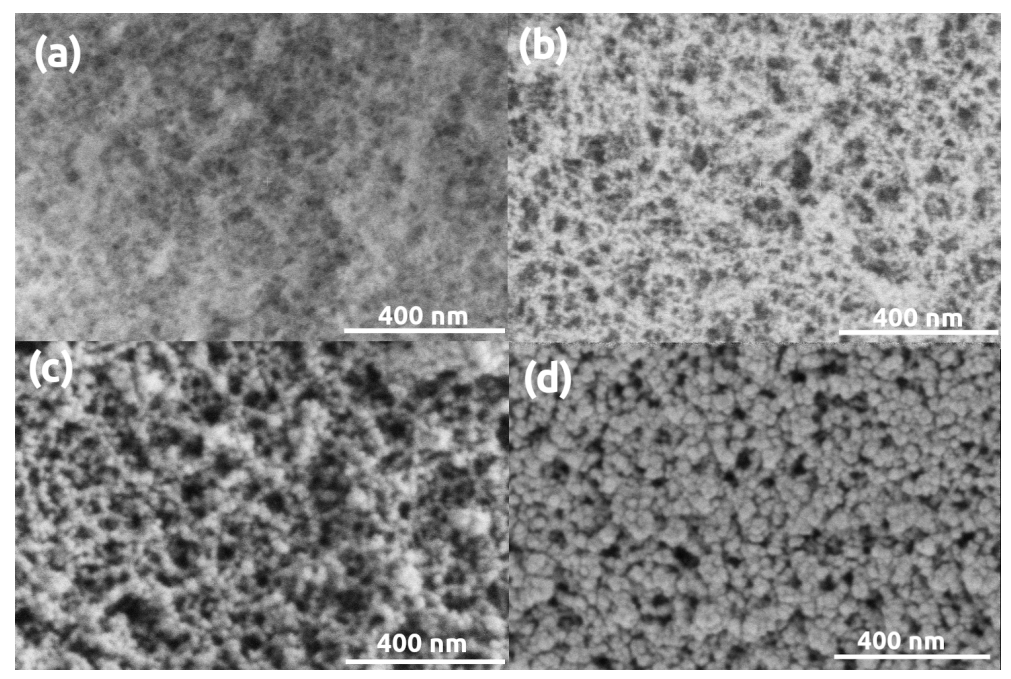

Figure 1. Low Voltage Scanning Electron Microscopy (LVSEM) images of silica aerogel samples. (a) Pristine, uncoated. (b-d) Sputter coated with $5 \mathrm{~nm}, 16 \mathrm{~nm}, 32 \mathrm{~nm}$ thick Au layers, respectively.

Figure 4 shows representative LVSEM images of pristine and gold coated Ca-alginate aerogel samples. It is clearly seen that the original nanostructure of Ca-alginate aerogel is drastically altered by the sputtered gold layer. The original open framework of the Ca-alginate aerogel is composed of short fibrils of 20-25 nm of thickness. Coating by $5 \mathrm{~nm}$ thick gold layer results in the appearance of globular Au nanoparticles on the junction of the fibrils. After a second round of sputtering, the concentration and the size of the nanoparticles increase, and the structure of the pristine Ca-alginate aerogel is completely hidden. 


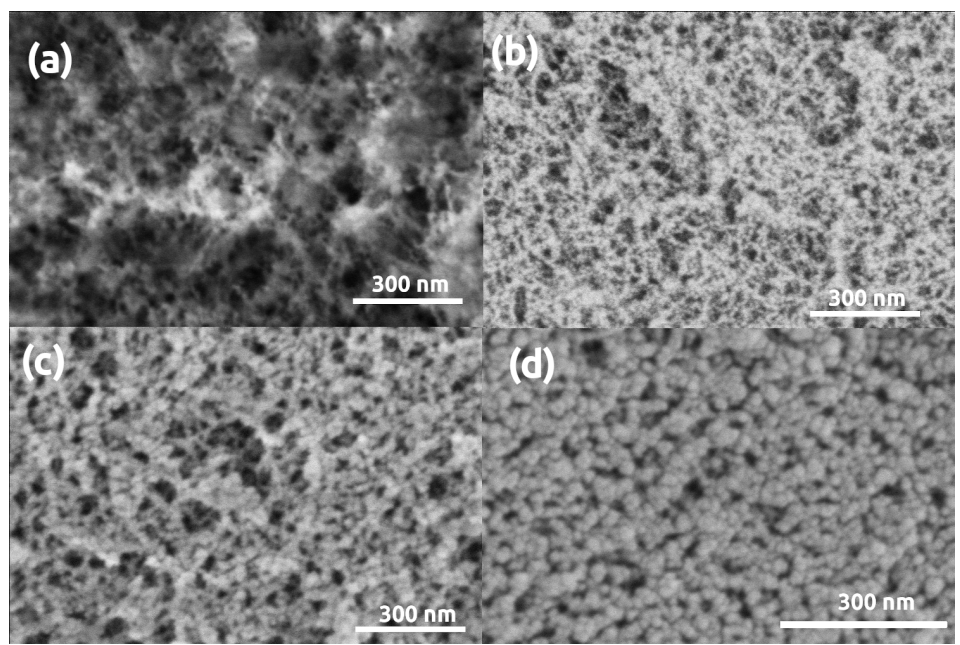

Figure 2. LVSEM images of silica-casein aerogel samples. (a) Pristine, uncoated. (b-d) Sputter coated with $5 \mathrm{~nm}, 16 \mathrm{~nm}, 32 \mathrm{~nm}$ thick Au layers, respectively.

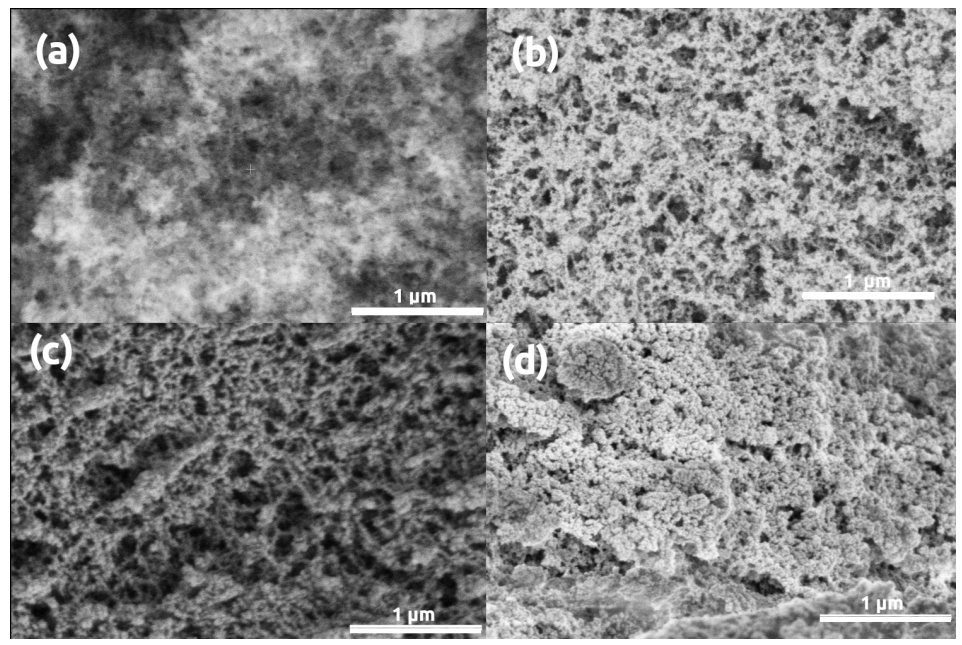

Figure 3. LVSEM images of silica-gelatin aerogel samples. (a) Pristine, uncoated. (b-d) Sputter coated with $5 \mathrm{~nm}, 16 \mathrm{~nm}, 32 \mathrm{~nm}$ thick Au layers, respectively.

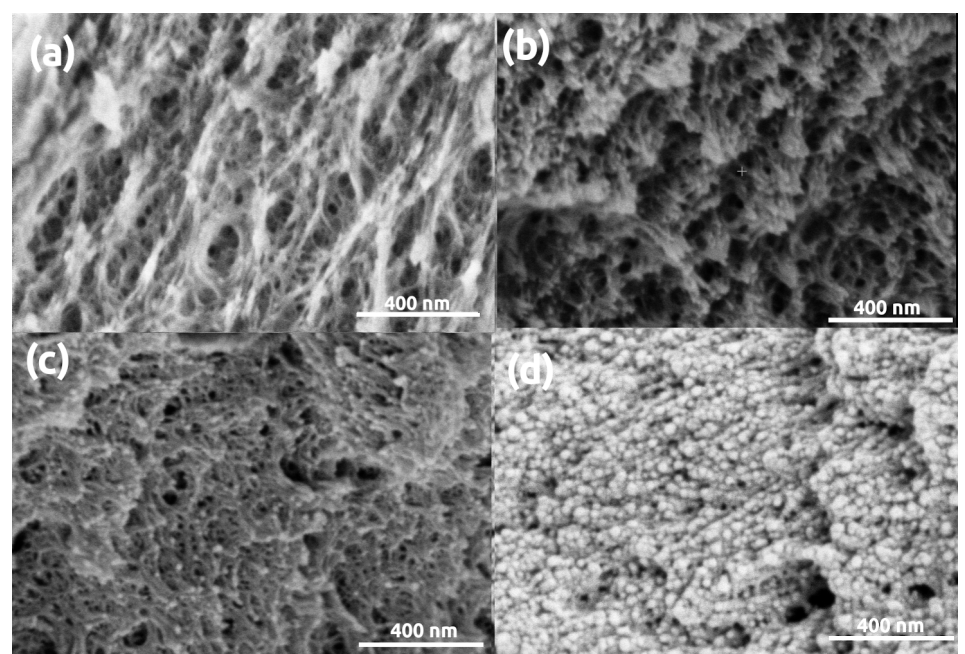

Figure 4. LVSEM images of Ca-alginate samples. (a) Pristine, uncoated. (b-d) Sputter coated with $5 \mathrm{~nm}, 16 \mathrm{~nm}, 32 \mathrm{~nm}$ thick Au layers, respectively. 
The morphologies of aramid polymer (polyimide and polyamide) aerogels are distinct from those of silica and biopolymers. Representative LVSEM images of polyimide aerogel samples are shown in Figure 5. The pristine polyimide aerogel is a loose network of polymer fibrils (struts) of ca. $28 \mathrm{~nm}$ thickness. After gold sputtering, the apparent thickness of fibrils significantly increases. Sputtering $16 \mathrm{~nm}$ coating causes the escalation of this phenomenon, that is, the apparent diameter of the fibrils doubles to ca. $50 \mathrm{~nm}$.

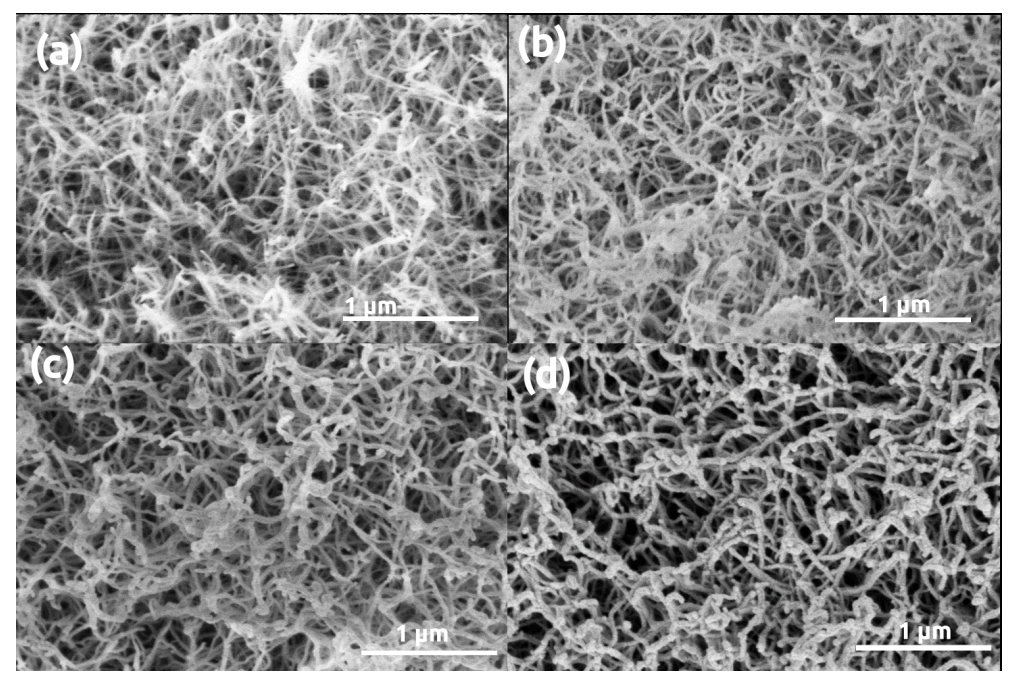

Figure 5. LVSEM images of polyimide aerogel samples. (a) Pristine, uncoated. (b-d) Sputter coated with $5 \mathrm{~nm}, 16 \mathrm{~nm}, 32 \mathrm{~nm}$ thick Au layers, respectively.

Representative LVSEM images of polyamide aerogel samples are shown in Figure 6. The three-dimensional structure of polyamide aerogel is composed of separated flat polymer strands that vary in size from a few nanometers to $100 \mathrm{~nm}$. Gold deposition causes significant changes in the morphology, that is, small Au nanoparticles appear on the surfaces and on the edges of the strands. The deposition of thick gold coating causes the aggregation of the polymer strands and the formation of Au islands that eventually cover the whole polymer surface. It is notable that the original polymer strands are flat, while the covered strands are cylindrical.

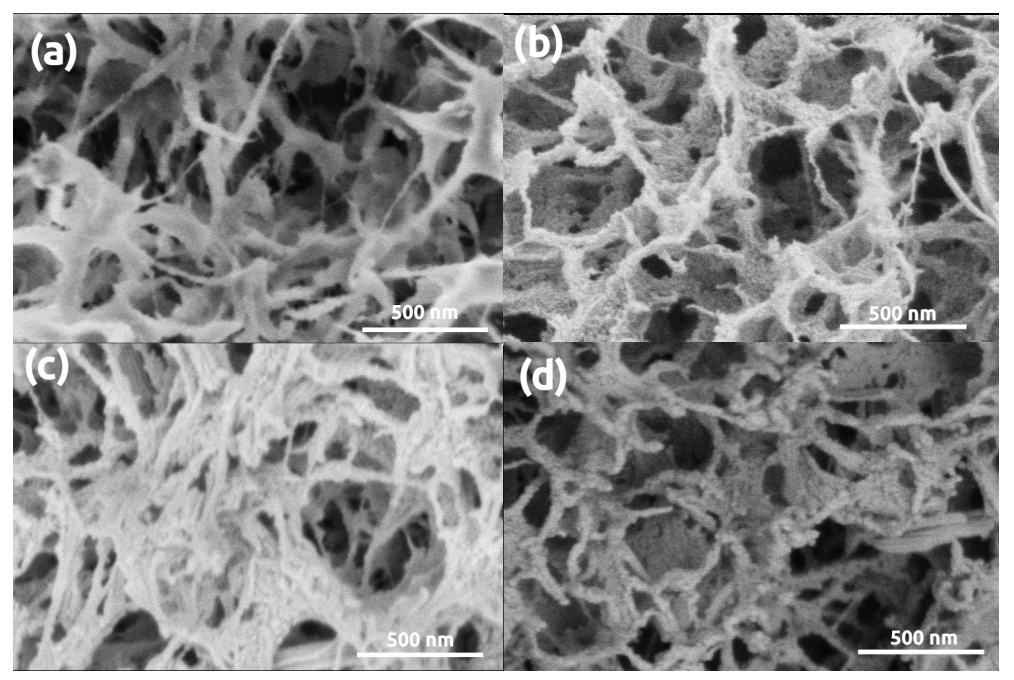

Figure 6. LVSEM images of polyamide aerogel samples. (a) Pristine, uncoated. (b-d) Sputter coated with $5 \mathrm{~nm}, 16 \mathrm{~nm}, 32 \mathrm{~nm}$ thick Au layers, respectively.

The $\mathrm{Ca}(\mathrm{II})$ crosslinked polyamide aerogel shows unique morphological changes as a result of gold sputtering (Figure 7). In the case of the $\mathrm{Ca}$ (II) crosslinked polyamide aerogel, 
the formation of Au nanoparticles does not take place, instead the polymer strands are uniformly covered by a continuous layer of Au even when sputtering a thin $5 \mathrm{~nm}$ gold coating. Eventually, the polymer strands aggregate due to their coverage by gold similarly to the behavior of the polyamide aerogel.

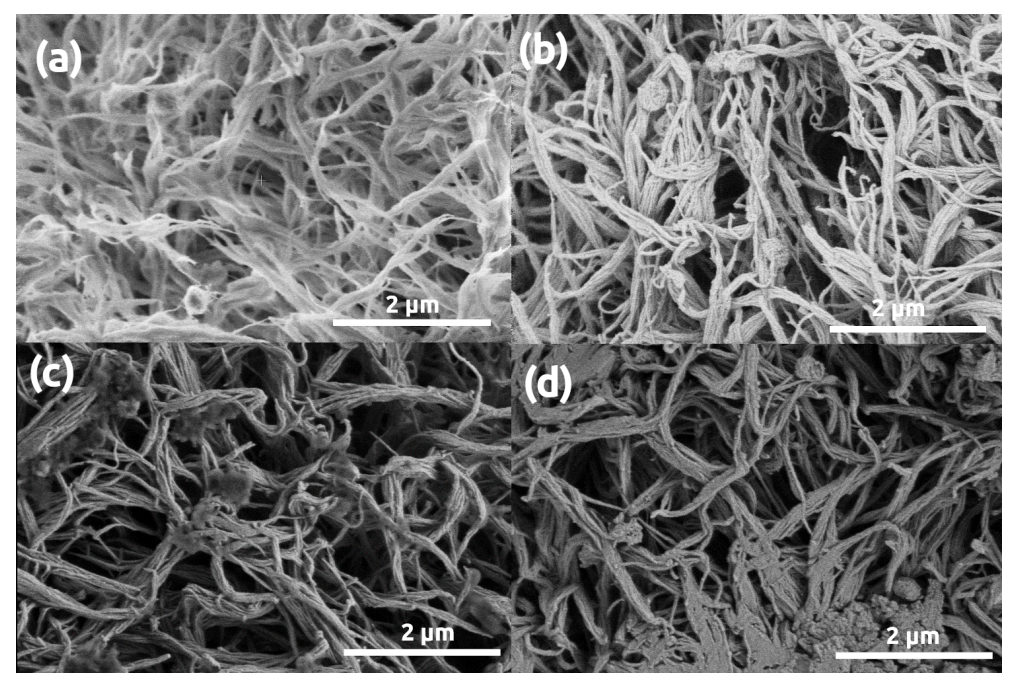

Figure 7. LVSEM images of polyamide-Ca(II) aerogel samples. (a) Pristine, uncoated. (b-d) Sputter coated with $5 \mathrm{~nm}, 16 \mathrm{~nm}, 32 \mathrm{~nm}$ thick Au layers, respectively.

The SEM images of the polyimide, polyamide and polyamide-Ca(II) aerogels (Figures 5-7) were evaluated using image analysis. Approximately 20 manual measurements were performed on the images of the pristine and the coated samples in order to determine the thickness of the primary fibrils and pore size. The results are given in a tabulated form in Supplementary Meterials. The numerical results are in very good agreement with the visual observations made on the SEM images. It is evident that fiber diameter dramatically increases as a consequence of gold coating in all polymer aerogels. Furthermore, pore sizes are dramatically altered in the case of the polyimide and polyamide-Ca(II) aerogels.

Images of the cellulose aerogel sample 1.0\%CL/1.0\%CL-P are shown in Figure 8a before and after Figure $8 \mathrm{~b}$ plasma coating. The image in Figure $8 \mathrm{c}$ was obtained in low vacuum $(70 \mathrm{~Pa})$ and it depicts the pristine sample. The image in Figure $8 \mathrm{~d}$ was obtained in high vacuum and it depicts the coated sample. The comparison of the images reveals the partial destruction of the interconnected regenerated cellulose network and the formation of globular Au particles on the surface caused by the coating procedure. The morphology of these cellulose aerogels have been investigated by small-angle X-ray scattering (SAXS). The results were reported in our previous publication [55]. The diameter of the fibrillar (cylindrical) network forming primary particles is ca. $4 \mathrm{~nm}$ in the pristine aerogel. In contrast, the size of the globular units visible in the LVSEM images of the coated samples exceed $50 \mathrm{~nm}$. Thus, the significant discrepancy between the morphologies derived from the SAXS results and visible on the LVSEM images of the coated sample clearly show the detrimental effect of gold sputtering.

In general, the observed morphological alterations of the very different types of aerogels are evidently caused by the sputtering of a metallic gold layer on their surfaces [46-48].

The characteristic size of the new morphological features formed on the aerogels after $\mathrm{Au}$ sputtering is a few tens of nanometers. The interaction volume for energy dispersive X-ray (EDX) analysis is much larger than the dimensions of these objects, because the penetration depth of electrons at $4 \mathrm{kV}$ (necessary overvoltage to generate an EDX signal from $\mathrm{Au}$ ) is ca. $160 \mathrm{~nm}$ according to Monte Carlo simulation performed with CASINO software [56]. Therefore, EDX mapping is not possible in the required resolution. In order to illustrate the distribution and localization of elements on a gold sputtered Ca-alginate aerogel sample surface, a SEM image is presented in Figure 9 that is a combination of the 
as-obtained in-lens SE and BSE signals. This image shows atomic number contrast: the brighter regions correspond to higher atomic numbers. Since the aerogel consists mainly of low atomic number elements $(\mathrm{C}, \mathrm{O}, \mathrm{H}, \mathrm{Ca})$ the bright globules in Figure 9 are Au particles.

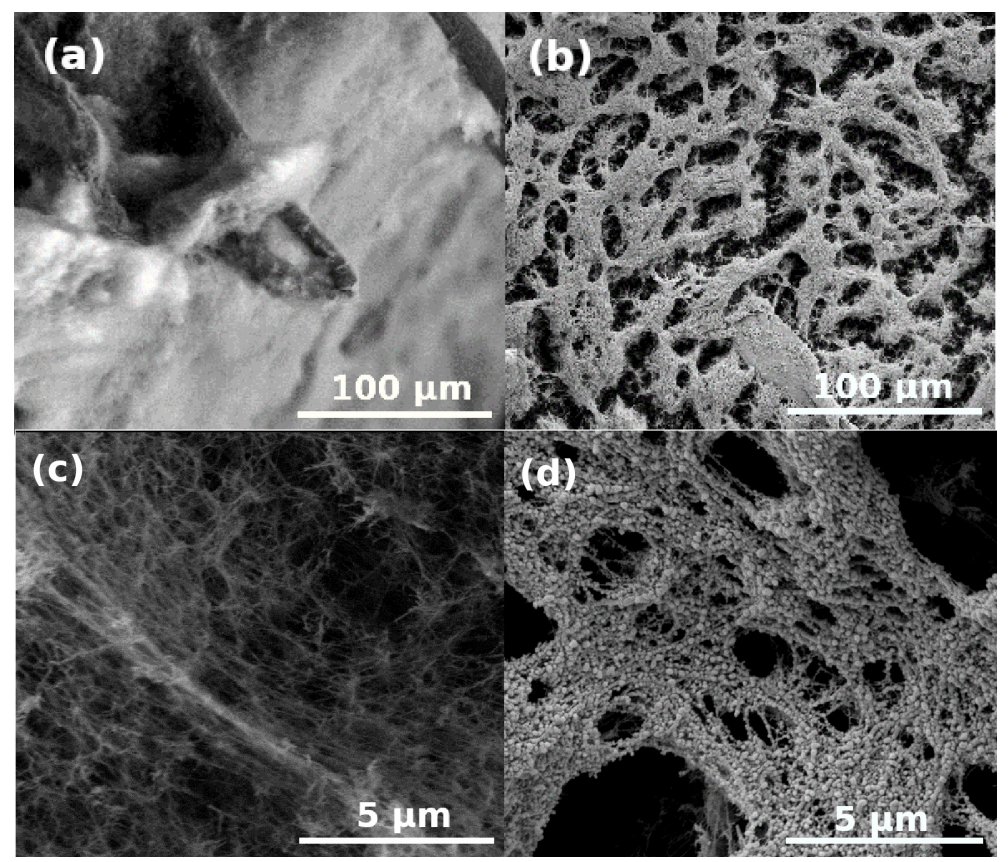

Figure 8. LVSEM images of cellulose aerogel samples. $(\mathbf{a}, \mathbf{c})$ Pristine, uncoated. $(\mathbf{b}, \mathbf{d})$ Plasma coated for $2.5 \mathrm{~min}$.

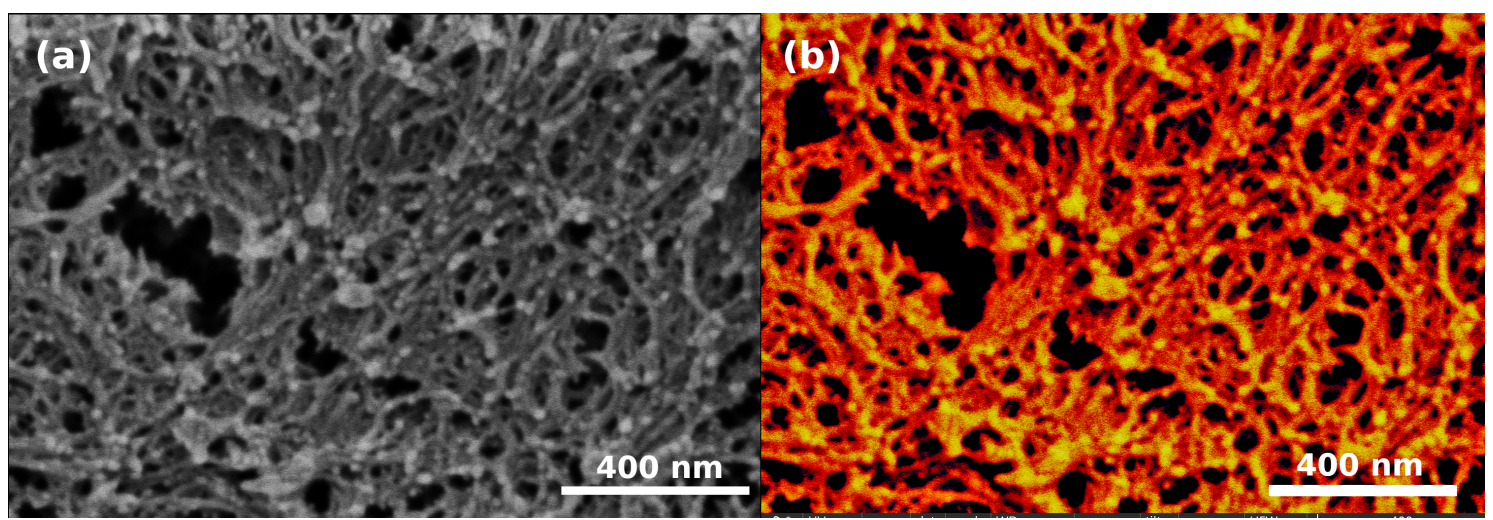

Figure 9. Images showing the combination of the as-obtained in-lens secondary electron (SE) and back scattered electron (BSE) signals of the $32 \mathrm{~nm}$ sputter coated Ca-alginate sample. The contrast correlates with atomic number: brighter regions correspond to higher atomic numbers. The aerogel consists of low atomic number elements, the bright spots are Au particles. The two images are identical, displayed in different color planes: (a) black/white and (b) red/white.

Gold atoms condense to the surface during the deposition and form clusters of $\mathrm{Au}$ nanoparticles, which is driven by the reduction of the surface energy of the system. The deposition of thin metallic films could take place by different mechanisms (e.g., Volmer-Weber, Frank-Van der Merwe or Stranski-Krastanov models) and strongly depends on the substrate as well as the deposition conditions (pressure, atmosphere, temperature, gas flow, applied power, chemical composition, nanostructure and purity of the target material) [57]. Barna and Adamik reported a general model of film growth [58]. In brief, the process starts with the nucleation and island growth of the sputtered material which is followed by the coalescence of islands and the formation of polycrystalline islands. Due to the ripening of the formed islands, an even film forms and the thickness of the thin layer increases. It 
has been reported earlier that the deposition of gold on the surfaces of non-conducting aerogels results in the formation of porous gold films with similar structures to those of the substrate aerogels. It is reasonable to assume that the phenomenon observed in the present study is of the same origin as the one resulting in the formation of these porous gold films [59]. Finally, ion-bombardment during sputtering could also have a significant effect on the structures of aerogels [60].

\section{Conclusions}

Experimental evidence is presented in this work unambiguously proving that gold sputtering changes the native morphologies of several different types of non-conducting nanostructured aerogels. The results are of considerable significance since the application of gold sputtering is part of the routine of scanning electron microscopy (SEM) imaging; however, this practice can lead to the misinterpretation of the morphologies of the nanostructured samples.

The structures of silica-based aerogels are dramatically altered when a sputtered conductive Au layer is deposited on them to facilitate SEM imaging. The original snowflakelike three-dimensional network of silica-based aerogels is covered by globular Au nanoparticles. The original fibrillar building blocks of the Ca-alginate backbone can erroneously be misinterpreted as globules when a thick layer of gold is sputtered on the sample. In the case of aramid polymer aerogels, the initial morphologies of polymer strands are still visible after gold sputtering, but the diameter of the strands can increase significantly, even by a factor of 2. The fine-structure of cellulose aerogel is partially destroyed as a consequence of gold sputtering.

The utilization of low voltage scanning electron microscopy (LVSEM) is strongly advised for investigating non-conducting aerogels, because this technique enables the acquisition of high-resolution images of representative pristine (uncoated) samples. These erroneous conclusions regarding the nanostructures and morphologies of aerogels evidently falsify characterization efforts, and ultimately falsify structure-property relationship theories. Therefore, the utilization of low voltage scanning electron microscopy (LVSEM) is strongly advised for investigating non-conducting aerogels, because this technique enables the acquisition of high-resolution images of representative pristine (uncoated) samples.

Supplementary Materials: The following are available online at https: / www.mdpi.com/2073-4 360/13/4/588/s1, Additional considerations on microscopy theory and experiment; experimental details on aerogel preparation; nitrogen porosimetry reports. Results of image analysis of LVSEM pictures of pristine and sputter coated polyimide, polyamide, polyamide-Ca(II) aerogel samples presented in Figures 5-7.

Author Contributions: C.C. and J.K. headed the research. L.J., K.M. designed and carried out the experiments. All authors wrote the manuscript, and all authors discussed the results and contributed to revisions. All authors have read and agreed to the published version of the manuscript.

Funding: Work carried out in the frame of COST Action CA18125 "Advanced Engineering and Research of AeroGels for Environment and Life Sciences" (AERoGELS), funded by the European Commission. The main aim of AERoGELS Action is to boost the development of aerogel-based products for biomedical and environmental applications through a multidisciplinary knowledgebased network that promotes exchange of ideas, expertise and outcomes, by encompassing European key actors in this field from technological, scientific and market points of view. This research has been financially supported by the National Research, Development and Innovation Office, Hungarian Science Foundation (OTKA: FK_17-124571 for J. Kalmár and K_17-124983 for I. Fábián). J. Kalmár is grateful for the financial support of the János Bolyai Research Scholarship of the Hungarian Academy of Sciences and for the support of the UNNP-20-5 (Bolyai+) New National Excellence Program of the Ministry of Innovation and Technology of Hungary. L. Juhász is grateful for the financial support of ÚNKP-20-3-II-DE-52 New National Excellence Program of the Ministry of Innovation and Technology of Hungary. The research was supported by the EU and co-financed by the European Regional Development Fund under the project GINOP 2.3.2-15-2016-00041. 
Data Availability Statement: The data presented in this study are available in the main body of the article and in Appendices A and B. Additional data presented in this study are available on request from the corresponding author.

Conflicts of Interest: The authors declare no conflict of interest.

\section{References}

1. García-González, C.; Budtova, T.; Durães, L.; Del Gaudio, P.; Gurikov, P.; Koebel, M.; Liebner, F.; Neagu, M.; Smirnova, I. An Opinion Paper on Aerogels for Biomedical and Environmental Applications. Molecules 2019, 24, 1815. [CrossRef] [PubMed]

2. Smirnova, I.; Gurikov, P. Aerogel Production: Current Status, Research Directions, and Future Opportunities. J. Supercrit. Fluids 2017, 134, 228-233. [CrossRef]

3. Ülker, Z.; Erkey, C. An Emerging Platform for Drug Delivery: Aerogel Based Systems. J. Control. Release 2014, 177, 51-63. [CrossRef] [PubMed]

4. Maleki, H. Recent Advances in Aerogels for Environmental Remediation Applications: A review. Chem. Eng. J. 2016, 300, 98-118. [CrossRef]

5. Maleki, H.; Durães, L.; García-González, C.; Del Gaudio, P.; Portugal, A.; Mahmoudi, M. Synthesis and Biomedical Applications of Aerogels: Possibilities and Challenges. Adv. Colloid Interface Sci. 2016, 236, 1-27. [CrossRef]

6. Stergar, J.; Maver, U. Review of Aerogel-based Materials in Biomedical Applications. J. Sol Gel Sci. Technol. 2016, 77, 738-752. [CrossRef]

7. Ganesan, K.; Budtova, T.; Ratke, L.; Gurikov, P.; Baudron, V.; Preibisch, I.; Niemeyer, P.; Smirnova, I.; Milow, B. Review on the Production of Polysaccharide Aerogel Particles. Materials 2018, 11, 2144. [CrossRef] [PubMed]

8. García-González, C.A.; López-Iglesias, C.; Concheiro, A.; Alvarez-Lorenzo, C. Chapter 16 Biomedical Applications of Polysaccharide and Protein Based Aerogels. In Biobased Aerogels: Polysaccharide and Protein-Based Materials; Sabu, T., Pothan, L.A., Mavelil-Sam, R., Eds.; RSC Chem.: Croydon, UK, 2018; pp. 295-323

9. Groult, S.; Budtova, T. Tuning Structure and Properties of Pectin Aerogels. Eur. Polym. J. 2018, 108, 250-261. [CrossRef]

10. Maleki, H.; Hüsing, N. Current Status, Opportunities and Challenges in Catalytic and Photocatalytic Applications of Aerogels: Environmental Protection Aspects. Appl. Catal. B 2018, 221, 530-555. [CrossRef]

11. Zhao, S.; Malfait, W.J.; Guerrero-Alburquerque, N.; Koebel, M.M.; Nyström, G. Biopolymer Aerogels and Foams: Chemistry, Properties, and Applications. Angew. Chem. Int. Ed. 2018, 57, 7580-7608. [CrossRef]

12. Li, X.; Li, Q.; Fei, J.; Jia, Y.; Xue, H.; Zhao, J.; Li, J. Self-Assembled Dipeptide Aerogels with Tunable Wettability. Angew. Chem. Int. Ed. 2020, 59, 11932-11936. [CrossRef] [PubMed]

13. Schwan, M.; Schettler, J.; Badaczewski, F.; Heinrich, C.; Smarsly, B.; Milow, B. The Effect of Pulverization Methods on the Microstructure of Stiff, Ductile, and Flexible Carbon Aerogels. J. Mater. Sci. 2020, 55, 5861-5879. [CrossRef]

14. Rege, A.; Preibisch, I.; Schestakow, M.; Ganesan, K.; Gurikov, P.; Milow, B.; Smirnova, I.; Itskov, M. Correlating Synthesis Parameters to Morphological Entities: Predictive Modeling of Biopolymer Aerogels. Materials 2018, 11, 1670. [CrossRef] [PubMed]

15. Buchtová, N.; Budtova, T. Cellulose Aero-, Cryo- and Xerogels: Towards Understanding of Morphology Control. Cellulose 2016, 23, 2585-2595. [CrossRef]

16. Zu, G.; Kanamori, K.; Maeno, A.; Kaji, H.; Nakanishi, K. Superflexible Multifunctional Polyvinylpolydimethylsiloxane-Based Aerogels as Efficient Absorbents, Thermal Superinsulators, and Strain Sensors. Angew. Chem. Int. Ed. 2018, 57, 9722-9727. [CrossRef]

17. Quignard, F.; Valentin, R.; Di Renzo, F. Aerogel Materials from Marine Polysaccharides. New J. Chem. 2008, 32, 1300-1310. [CrossRef]

18. Goncalves, V.; Gurikov, P.; Poejo, J.; Matias, A.; Heinrich, S.; Duarte, C.; Smirnova, I. Alginate-based Hybrid Aerogel Microparticles for Mucosal Drug Delivery. Eur. J. Pharm. Biopharm. 2016, 107, 160. [CrossRef] [PubMed]

19. Paraskevopoulou, P.; Chriti, D.; Raptopoulos, G.; Anyfantis, G.C. Synthetic Polymer Aerogels in Particulate Form. Materials 2019, 12, 1543. [CrossRef]

20. Meador, M.A.B.; Alemán, C.R.; Hanson, K.; Ramirez, N.; Vivod, S.L.; Wilmoth, N.; McCorkle, L. Polyimide Aerogels with Amide Cross-Links: A Low Cost Alternative for Mechanically Strong Polymer Aerogels. ACS Appl. Mater. Interfaces 2015, 7, 1240-1249. [CrossRef]

21. Williams, J.C.; Nguyen, B.N.; McCorkle, L.; Scheiman, D.; Griffin, J.S.; Steiner, S.A.; Meador, M.A.B. Highly Porous, Rigid-Rod Polyamide Aerogels with Superior Mechanical Properties and Unusually High Thermal Conductivity. ACS Appl. Mater. Interfaces 2017, 9, 1801-1809. [CrossRef] [PubMed]

22. Williams, J.C.; Meador, M.A.B.; McCorkle, L.; Mueller, C.; Wilmoth, N. Synthesis and Properties of Step-Growth Polyamide Aerogels Cross-linked with Triacid Chlorides. Chem. Mater. 2014, 26, 4163-4171. [CrossRef]

23. Winkler, R.; Ré, E.; Arrachart, G.; Pellet-Rostaing, S. Impact of the Solvent Structuring in Water/tert-butanol Mixtures on the Assembly of Silica Nanoparticles to Aerogels. Langmuir 2019, 35, 7905-7915. [CrossRef]

24. Talley, S.; Vivod, S.; Nguyen, B.; Meador, M.; Radulescu, A.; Moore, R. Hierarchical Morphology of Poly(ether ether ketone) Aerogels. ACS Appl. Mater. Interfaces 2019, 11, 31508-31519. [CrossRef] [PubMed] 
25. Osorio, D.A.; Lee, B.E.; Kwiecien, J.M.; Wang, X.; Shahid, I.; Hurley, A.L.; Cranston, E.D.; Grandfield, K. Cross-linked Cellulose Nanocrystal Aerogels as Viable Bone Tissue Scaffolds. Acta Biomater. 2019, 87, 152-165. [CrossRef] [PubMed]

26. Rege, A.; Schwan, M.; Chernova, L.; Hillgärtner, M.; Itskov, M.; Milow, B. Microstructural and Mechanical Characterization of Carbon Aerogels: An In-situ and Digital Image Correlation-based Study. J. Non Cryst. Solids 2020, 529, 119568. [CrossRef]

27. Ganesan, K.; Barowski, A.; Ratke, L.; Milow, B. Influence of Hierarchical Porous Structures on the Mechanical Properties of Cellulose Aerogels. J. Sol Gel Sci. Technol. 2019, 89, 156-165. [CrossRef]

28. Ganesan, K.; Barowski, A.; Ratke, L. Gas Permeability of Cellulose Aerogels with a Designed Dual Pore Space System. Molecules 2019, 24, 2688. [CrossRef] [PubMed]

29. Baldino, L.; Cardea, S.; Scognamiglio, M.; Reverchon, E. A New Tool to Produce Alginate-based Aerogels for Medical Applications, by Supercritical Gel Drying. J. Supercrit. Fluids 2019, 146, 152-158. [CrossRef]

30. Maleki, H.; Shahbazi, M.A.; Montes G.S.K.; Hosseini, S.H.; Eskandari, M.R.; Zaunschirm, S.; Verwanger, T.; Mathur, D.S.; Milow, B.; Krammer, B.; et al. Mechanically Strong Silica-Silk Fibroin Bioaerogel: A Hybrid Scaffold with Ordered Honeycomb Micromorphology and Multiscale Porosity for Bone Regeneration. ACS Appl. Mater. Interfaces 2019, 11, 17256-17269. [CrossRef] [PubMed]

31. Zhu, Z.; Snellings, G.; Koebel, M.; Malfait, W. Superinsulating Polyisocyanate Based Aerogels: A Targeted Search for the Optimum Solvent System. ACS Appl. Mater. Interfaces 2017, 9, 18222-18230. [CrossRef]

32. Rege, A.; Ratke, L.; Külcü, İ.D.; Gurikov, P. Stiffening of Biopolymer Aerogel Networks Upon Wetting: A Model-based Study. J. Non Cryst. Solids 2020, 531, 119859. [CrossRef]

33. Dosta, M.; Jarolin, K.; Gurikov, P. Modelling of Mechanical Behavior of Biopolymer Alginate Aerogels Using the Bonded-Particle Model. Molecules 2019, 24, 2543. [CrossRef] [PubMed]

34. Franco, P.; Marco, I.D. Supercritical $\mathrm{CO}_{2}$ Adsorption of Non-steroidal Anti-inflammatory Drugs into Biopolymer Aerogels. J. $\mathrm{CO}_{2}$ Util. 2020, 36, 40-53. [CrossRef]

35. Gorshkova, N.; Brovko, O.; Palamarchuk, I.; Bogolitsyn, K.; Bogdanovich, N.; Ivakhnov, A.; Chukhchin, D.; Arkhilin, M. Formation of Supramolecular Structure in Alginate/chitosan Aerogel Materials during Sol-gel Synthesis. J. Sol Gel Sci. Technol. 2020, 95, 101-108. [CrossRef]

36. Rennhofer, H.; Plappert, S.; Lichtenegger, H.; Bernstorff, S.; Fitzka, M.; Nedelec, J.M.; Liebner, F. Insight into the Nanostructure of Anisotropic Cellulose Aerogels upon compression. Soft Matter 2019, 15, 101-108. [CrossRef]

37. Stachewicz, U.; Szewczyk, P.K.; Kruk, A.; Barber, A.H.; Czyrska-Filemonowicz, A. Pore Shape and Size Dependence on Cell Growth into Electrospun Fiber Scaffolds for Tissue Engineering: 2D and 3D Analyses using SEM and FIB-SEM Tomography. Mater. Sci. Eng. C 2019, 95, 397-408. [CrossRef]

38. Price, C.W.; McCarthy, P.L. Low-voltage scanning electron microscopy of low-density materials. Scanning 1988, 10, 29-36. doi:10.1002/sca.4950100106. [CrossRef]

39. Lázár, I.; Fábián, I. A Continuous Extraction and Pumpless Supercritical $\mathrm{CO}_{2}$ Drying System for Laboratory-Scale Aerogel Production. Gels 2016, 2, 26. [CrossRef] [PubMed]

40. Kalmár, J.; Kéri, M.; Erdei, Z.; Bányai, I.; Lázár, I.; Lente, G.; Fábián, I. The Pore Network and the Adsorption Characteristics of Mesoporous Silica Aerogel: Adsorption, Kinetics on a Timescale of Seconds. RSC Adv. 2015, 5, 107237-107246. [CrossRef]

41. Veres, P.; Kéri, M.; Bányai, I.; Lázár, I.; Fábián, I.; Domingo, C.; Kalmár, J. Mechanism of Drug Release from Silica-gelatin Aerogel-Relationship between Matrix Structure and Release Kinetics. Colloids Surf. B 2017, 152, 229-237. [CrossRef]

42. Kéri, M.; Forgács, A.; Papp, V.; Banyai, I.; Veres, P.; Len, A.; Dudás, Z.; Fábián, I.; Kalmár, J. Gelatin Content Governs Hydration Induced Structural Changes in Silica-gelatin Hybrid Aerogels-Implications in Drug Delivery. Acta Biomater. 2020, 105, 131-145. [CrossRef] [PubMed]

43. Lázár, I.; Forgács, A.; Horváth, A.; Király, G.; Nagy, G.; Len, A.; Dudás, Z.; Papp, V.; Balogh, Z.; Moldován, K.; et al. Mechanism of Hydration of Biocompatible Silica-casein Aerogels Probed by NMR and SANS Reveal Backbone Rigidity. Appl. Surf. Sci. 2020, 531, 147232. [CrossRef]

44. Preibisch, I.; Niemeyer, P.; Yusufoglu, Y.; Gurikov, P.; Milow, B.; Smirnova, I. Polysaccharide-Based Aerogel Bead Production via Jet Cutting Method. Materials 2018, 11, 1287. [CrossRef]

45. Schimper, C.B.; Pachschwoell, P.S.; Hettegger, H.; Neouze, M.A.; Nedelec, J.M.; Wendland, M.; Rosenau, T.; Liebner, F. Aerogels from Cellulose Phosphates of Low Degree of Substitution: A TBAF·H2O/DMSO Based Approach. Molecules 2020, $25,1695$. [CrossRef] [PubMed]

46. Thornton, J. Influence of Apparatus Geometry and Deposition Condition the Structure and Topography of Thick Sputtered Coatings. J. Vac. Sci. Technol. 1974, 11, 666-670. [CrossRef]

47. Sree Harsha, K. Chapter 9-Nucleation and Growth of Films. In Principles of Vapor Deposition of Thin Films; Sree Harsha, K., Ed.; Elsevier: Oxford, UK, 2006; pp. 685-829.

48. Greene, J. Chapter 12-Thin Film Nucleation, Growth, and Microstructural Evolution: An Atomic Scale View. In Handbook of Deposition Technologies for Films and Coatings, 3rd ed.; Martin, P.M., Ed.; William Andrew Publishing: Boston, MA, USA, 2010; pp. 554-620.

49. Švorčík, V.; Kolská, Z.; Luxbacher, T.; Mistrík, J. Properties of Au Nanolayer Sputtered on Polyethyleneterephthalate. Mater. Lett. 2010, 64, 611-613. [CrossRef] 
50. Alfonso, E.; Olaya, J.; Cubillos, G. Thin Film Growth Through Sputtering Technique and Its Applications. In Crystallization; Andreeta, M.R.B., Ed.; IntechOpen: Rijeka, Croatia, 2012; pp. 397-432.

51. Pondelak, A.; Rosi, F.; Maurich, C.; Miliani, C.; Škapin, S.D.; Sever Škapin, A. The Role of Relative Humidity on Crystallization of Calcium Carbonate from Calcium Acetoacetate Precursor. Appl. Surf. Sci. 2020, 506, 144768. [CrossRef]

52. Sołtys-Mróz, M.; Syrek, K.; Pierzchała, J.; Wiercigroch, E.; Malek, K.; Sulka, G.D. Band Gap Engineering of Nanotubular $\mathrm{Fe}_{2} \mathrm{O}_{3}-\mathrm{TiO}_{2}$ Photoanodes by Wet Impregnation. Appl. Surf. Sci. 2020, 517, 146195. [CrossRef]

53. Erdman, N.; Bell, D.C.; Reichelt, R. Scanning Electron Microscopy. In Springer Handbook of Microscopy; Hawkes, P., Spence, J.C., Eds.; Springer International Publishing: Cham, Switzerland, 2019; pp. 229-318

54. Huber, L.; Zhao, S.; Malfait, W.J.; Vares, S.; Koebel, M.M. Fast and Minimal-Solvent Production of Superinsulating Silica Aerogel Granulate. Angew. Chem. Int. Ed. 2017, 56, 4753-4756. [CrossRef] [PubMed]

55. Pircher, N.; Carbajal, L.; Schimper, C.B.; Bacher, M.; Rennhofer, H.; Nedelec, J.M.; Lichtenegger, H.; Rosenau, T.; Liebner, F. Impact of Selected Solvent Systems on the Pore and Solid Structure of Cellulose Aerogels. Cellulose 2016, 23, 1949-1966. [CrossRef] [PubMed]

56. Hovington, P.; Drouin, D.; Gauvin, R. CASINO: A new monte carlo code in C language for electron beam interaction-Part I: Description of the program. Scanning 1997, 19. [CrossRef]

57. Al-Alwany, R. Effect of Working Pressure on the Structural and Morphological Properties of Gold Nanoparticles Prepared by a DC Magnetron Sputtering Technique. J. Crit. Rev. 2020, 7, 1-5. [CrossRef]

58. Barna, P.; Adamik, M. Fundamental Structure Forming Phenomena of Polycrystalline Films and the Structure Zone Models. Thin Solid Film. 1998, 317, 27-33. [CrossRef]

59. Ron, R.; Gachet, D.; Rechav, K.; Salomon, A. Direct Fabrication of 3D Metallic Networks and Their Performance. Adv. Mater. 2017, 29, 1604018. [CrossRef]

60. Kim, H.R.; Park, H.H. The Effect of $\mathrm{Ar}^{+}$Ion Bombardment on $\mathrm{SiO}_{2}$ Aerogel Film. JJAP 1998, 37, 6955-6958. [CrossRef] 